\title{
Sensory Ganglionopathy and the Blink Reflex: Electrophysiological Features
}

\author{
Taimour Alam, Alexander StJ.E. Barker, James J.P. Alix, Marios Hadjivassiliou, \\ Dasappaiah G. Rao
}

\begin{abstract}
Background: Sensory ganglionopathy (SG) is characterised by asymmetrical sensory fibre degeneration, with the primary pathology occurring at the level of the dorsal root ganglion. It is seen in the context of autoimmune, paraneoplastic, and degenerative disorders. There is limited literature examining the electrophysiological correlate of the trigeminal ganglion and associated pathways, the blink reflex (BR), in cases of SG. Previous work has suggested that the BR is preserved in cases of SG associated with paraneoplasia. Methods: The local clinical neurophysiology database was searched for patients diagnosed with SG from peripheral nerve conduction studies in whom the BR was performed. Twenty-six patients were included in the final analysis. Results: Sjögren's syndrome constituted the most common SG aetiology (8/26), followed by idiopathic cases (7/26) and paraneoplasia (5/26). BR abnormalities were seen in 9 of the 26 patients $(34.6 \%)$ across all aetiologies. No patients reported sensory disturbance in the distribution of the trigeminal nerve, indicating that the changes noted are subclinical. Three patients showed abnormality of the R1 response; in the remaining six patients, only R2 responses were affected. Conclusions: Subclinical abnormalities of both R1 and R2 can be seen in the context of SG of varying aetiologies, including paraneoplasia. Performing the BR in patients with suspected of having SG may be helpful in providing additional evidence of patchy sensory fibre involvement that is characteristic of the disease.
\end{abstract}

RÉSUMÉ: Gangliopathie sensitive et réflexe de clignement : caractéristiques électrophysiologiques. Contexte: La gangliopathie sensitive (GS) est caractérisée par une dégénérescence asymétrique des fibres sensitives, la pathologie primaire étant localisée au niveau du ganglion spinal. On la rencontre dans le contexte de maladies autoimmunes, paranéoplasiques ou dégénératives. Il existe peu de littérature qui examine les caractéristiques électrophysiologiques du ganglion du trijumeau et les voies qui y sont associée ainsi que le réflexe de clignement (RC) chez les patients présentant une GS. Selon des études antérieures, le RC est conservé chez les cas de GS associée à une paranéoplasie. Méthode: Nous avons identifié dans la base de données de neurophysiologie clinique locale des patients ayant reçu un diagnostic de GS basé sur des études de conduction au niveau du nerf périphérique et chez qui le RC a été recherché. Vingt-six patients ont été inclus dans l'analyse finale. Résultats: Le syndrome de Sjögren était l'étiologie la plus fréquente de GS (8/26), suivi de cas idiopathiques (7/26) et de paranéoplasies (5/26). Des anomalies du RC ont été constatées chez 9 des 26 patients (34,6\%), toutes étiologies confondues. Aucun patient n'a rapporté de problèmes sensitifs dans le territoire du nerf trijumeau indiquant que les changements notés sont subcliniques. Trois patients présentaient une réponse R1 anormale. Chez les 6 autres patients, seulement les réponses R2 étaient touchées. Conclusions: Des anomalies subcliniques de R1 et R2 peuvent exister dans le contexte de GS d'étiologies variées, dont la paranéoplasie. Chez les patients chez qui on soupçonne une GS, le RC peut aider à fournir des indices additionnels d'une atteinte asymétrique des fibres sensitives, ce qui est caractéristique de la maladie.

Keywords: electrodiagnostic studies, paraneoplastic conditions, sensory neurons

doi:10.1017/cjn.2015.361

Can J Neurol Sci. 2016; 43: 385-389

\section{INTRODUCTION}

Sensory ganglionopathy (SG) is a disorder characterised by damage and dysfunction of the sensory neuronal cell bodies lying in the dorsal root ganglion. ${ }^{1}$ It may be seen in degenerative conditions such as Friedreich's ataxia ${ }^{2}$ and is well recognised in the context of paraneoplastic disorders. ${ }^{3}$ We and other authors have also reported SG in the context of autoimmune disorders such as Sjögren's syndrome and gluten sensitivity. ${ }^{4,5}$ Diagnosis can be difficult, and a set of diagnostic criteria, using both clinical and electrophysiological features, has been proposed. ${ }^{6}$

The trigeminal ganglion is easily assessed with electrical stimulation of the supraorbital nerve with recording electrodes placed over the orbicularis oculi muscles bilaterally. The recorded responses are termed the Blink Reflex (BR). Responses used most often in clinical practice consist of an initial response ipsilateral to the stimulus, termed $\mathrm{R} 1$, followed by a later response seen both ipsilaterally and contralaterally, known as R2. Fibres conducting the R1 synapse within the main trigeminal nucleus in the pons, forming a circuit with the facial nucleus via interneurons that then lead back to the facial muscles. The pathway for the $\mathrm{R} 2$ response is polysynaptic, with afferent fibres

From the Department of Clinical Neurophysiology, Royal Hallamshire Hospital, Sheffield, UK (TA, ASEB, JJPA, DGR) and Department of Neurology, Royal Hallamshire Hospital, Sheffield, UK (MH).

Received May 5, 2015. Final Revisions Submitted September 10, 2015. Correspondence to: Taimour Alam, Royal Hallamshire Hospital, Glossop Road, Sheffield, S10 2JF UK.

Email: taimouralam@gmail.com 
passing through the spinal trigeminal tract to the spinal trigeminal nucleus. From there, connections exist to ipsilateral and contralateral facial nuclei giving rise to bilateral $\mathrm{R} 2$ responses following unilateral stimulation. ${ }^{7}$ Abnormalities of the latencies for R1 and R2 responses are used most frequently in clinical practice.

In the context of sensory ganglionopathy, clinical evidence of sensory involvement of the trigeminal nerve innervated territory is well established in various aetiologies, including Sjögren's syndrome, paraneoplasia, and acute autonomic and sensory neuropathy. ${ }^{8-10}$ There are, however, few previous reports documenting the electrophysiological features of the BR in association with SG. ${ }^{1,12}$ In the largest case series, paraneoplastic disorders were not associated with any abnormalities. ${ }^{11}$ The BR has also been used to delineate subclinical cranial nerve involvement in patients with diabetes mellitus. ${ }^{13,14}$ The purpose of the present study was to determine if there was evidence of subclinical involvement of trigeminal fibres in the context of SG diagnoses made in association with a variety of conditions and to characterise any abnormalities present.

\section{MeTHODS}

We reviewed the local electromyography database in the Department of Clinical Neurophysiology, Royal Hallamshire Hospital, Sheffield, England, over an 11-year period. We performed a search for patients diagnosed with SG, or possible SG, in whom BR data were available. This resulted in 27 patients being identified. One patient was subsequently excluded because of an interim clinical episode of Miller-Fisher syndrome, which could have accounted for abnormalities in the BR responses. The included cases were scrutinised for the information displayed in Table 1. Based on the information obtained, the diagnostic criteria scoring system for SG proposed by Camdessanche et al was completed for all patients. ${ }^{6}$

Electrophysiological examinations were performed using Nicolet EMG machines and Viking select software. Recording technique and normative data were taken from established departmental normative values that are very similar to published reference values. ${ }^{15}$ Maximum latency is $13 \mathrm{~ms}$ for $\mathrm{R} 1,41 \mathrm{~ms}$ for ipsilateral R2, and $44 \mathrm{~ms}$ for contralateral R2. The maximum sideto-side difference in latency is $1.8 \mathrm{~ms}$ for $\mathrm{R} 1$ and $5.7 \mathrm{~ms}$ and $9.4 \mathrm{~ms}$ for ipsilateral and contralateral R2, respectively.

Sensory responses were recorded from the median, ulnar, radial, lateral antebrachial, and medial antebrachial nerves in the upper limbs and sural and peroneal nerves in the lower limbs. Motor studies were performed on the median, ulnar, peroneal, and tibial nerves. The number of peripheral nerves examined varied between patients, depending upon how quickly asymmetrical, non-length dependent and/or exclusively sensory involvement could be established. All patients had sensory responses from at least three limbs recorded, with 17 patients having all four limbs examined. Motor responses were recorded from a minimum of two limbs, with 17 patients having more than two limbs examined.

\section{Results}

Analysis of the clinical examinations of all patients revealed that all but three were ataxic. Asymmetrical sensory loss at the time of initial medical assessment was documented in 13 patients.
Five individuals had clinical involvement of the lower limbs only, three suffered upper limb involvement only, and the remaining group had both upper and lower limb involvement. No patients reported sensory disturbance to the face or intraorally. Pain in the distal upper limbs was reported by two patients early in the course of the disease, but was otherwise not noted to be a prominent feature. Sjögren's syndrome was recognised as the most common aetiology for SG (Table 1). No sensory responses were recordable from either the upper or lower limbs during nerve conduction studies in seven patients (Table 1). The SG diagnostic criteria scores, postulated aetiologies, and BR abnormalities are given in Table 2. All but two patients scored higher than 6.5 on the diagnostic criteria score for a diagnosis of SG. The two patients that did not achieve a score higher than 6.5 had clinical involvement of the lower limbs only, with one patient not clearly having clinical asymmetry and one not fulfilling criteria for Sensory Nerve Action Potential abnormality in the upper limbs.

Analysis of the BR recordings revealed abnormal responses in 9 of 26 patients (34.6\%). In two patients, isolated abnormality of the $\mathrm{R} 1$ response was noted (Table 2). One patient showed abnormality of the R1 and R2. In the remaining six patients, only R2 abnormalities were seen. Four of nine patients with abnormal BR studies had magnetic resonance imaging of the brain performed. No evidence of brainstem pathology was apparent in any of the cases. In one additional patient with an abnormal BR, full-body positron emission tomography scan was normal. Interestingly, the BR was normal in five of seven patients in whom no sensory responses could be recorded from the limbs.

\section{DISCUSSION}

In our cohort, six of 26 patients had abnormalities of R2 and three patients had R1 abnormalities. The R1 response is generally regarded as the more robust response in terms of both latency and resistance to modulation from external factors. Our data suggest that subclinical involvement of trigeminal fibres can be seen in patients with $\mathrm{SG}$, with variable involvement of the R1 and R2 responses.

Overall, our most frequent observation was that of disturbance to $\mathrm{R} 2$, with abnormalities ranging from mild prolongation of R2 latency to absence of the $\mathrm{R} 2$ response. The pathologic correlate of this finding would appear to be either the more selective involvement of cell bodies of fibres conducting the $\mathrm{R} 2$ response within the Gasserian ganglion, or in the multisynaptic central pathways responsible for R2 generation. Previous work looking at cranial reflexes in patients with Sjögren's syndrome and SG postulated that the likely site of pathology was at the level of the Gasserian ganglion. ${ }^{16}$ We suspect that the abnormalities seen in our cohort are also more likely to be secondary to involvement of the Gasserian ganglion.

It is interesting to note that five patients had no sensory responses recordable from the limbs, but had a normal BR. This disparity could be explained by the fact that the fibres conducting both R1 and $\mathrm{R} 2$ are thought to be of thin- to medium-thickness myelinated fibres, ${ }^{7,17}$ unlike the large A-alpha fibres responsible for sensory nerve action potential generation on examination of the limbs. There is some suggestion that the A-delta fibres in the limbs are relatively spared in patients with $\mathrm{SG}^{18}$; this disparity in fibre type could explain why the BR appears relatively preserved or shows modest abnormality in the context of severe involvement of the limbs. 
Table 1: Etiological, clinical, and electrophysiological data used in calculating the diagnostic criteria score for all patients

\begin{tabular}{|c|c|c|c|c|c|c|c|c|c|c|c|c|}
\hline \multirow[b]{3}{*}{ Patient } & \multirow[b]{3}{*}{ Age } & \multirow[b]{3}{*}{ Sex } & \multirow[b]{3}{*}{ Etiology } & \multirow[b]{3}{*}{$\begin{array}{c}\text { Duration of } \\
\text { symptoms in } \\
\text { years }\end{array}$} & \multicolumn{3}{|c|}{ Clinical features } & \multicolumn{4}{|c|}{ Electrophysiology } & \multirow[b]{3}{*}{$\begin{array}{c}\text { Diagnostic } \\
\text { criteria score }\end{array}$} \\
\hline & & & & & & & & \multirow{2}{*}{$\begin{array}{c}\text { (Upper limb) } \\
\text { At least } 1 \text { SNAP } \\
\text { unrecordable? }\end{array}$} & \multirow{2}{*}{$\begin{array}{c}\text { (Upper limb) } \\
\text { 3 SNAPs } \\
<30 \% \text { of } \\
\text { LLN? }\end{array}$} & \multirow{2}{*}{$\begin{array}{c}\text { (Lower limb) } \\
<2 \text { motor nerve } \\
\text { conduction studies } \\
\text { abnormal? }\end{array}$} & \multirow[b]{2}{*}{$\begin{array}{l}\text { Any SNAPs } \\
\text { recordable? }\end{array}$} & \\
\hline & & & & & $\begin{array}{c}\text { Ataxia } \\
\text { present? }\end{array}$ & $\begin{array}{l}\text { Asymmetry in } \\
\text { sensory loss? }\end{array}$ & $\begin{array}{l}\text { Upper/lower } \\
\text { limb } \\
\text { involvement? }\end{array}$ & & & & & \\
\hline 1 & 69 & $\mathrm{M}$ & Gluten/celiac & 29 & Yes & Yes & Both & Yes & - & Yes & No & 12.7 \\
\hline 2 & 41 & $\mathrm{~F}$ & Gluten/celiac & 1 & No & Yes & Both & No & No & Yes & Yes & 6.8 \\
\hline 3 & 61 & M & Gluten/celiac & 1 & Yes & Yes & Both & No & No & Yes & Yes & 9.9 \\
\hline 4 & 20 & $\mathrm{M}$ & Friedreich's & 5 & Yes & No & Both & Yes & - & Yes & No & 11 \\
\hline 5 & 24 & M & Friedreich's & 10 & Yes & No & Both & Yes & - & Yes & No & 11 \\
\hline 6 & 20 & $\mathrm{~F}$ & Friedreich's & 13 & Yes & No & Both & Yes & - & Yes & No & 11 \\
\hline 7 & 76 & $\mathrm{~F}$ & Idiopathic & 4 & Yes & Yes & Lower only & Yes & - & Yes & No & 10.7 \\
\hline 8 & 67 & $\mathrm{~F}$ & Idiopathic & 6 & Yes & Yes & Both & Yes & - & Yes & Yes & 12.7 \\
\hline 9 & 73 & $\mathrm{~F}$ & Idiopathic & 20 & Yes & No & Both & Yes & - & Yes & Yes & 11 \\
\hline 10 & 73 & $\mathrm{~F}$ & Idiopathic & 7 & Yes & Yes & Lower only & No & No & No & Yes & 4.8 \\
\hline 11 & 54 & $\mathrm{M}$ & Idiopathic & 16 & Yes & Yes & Both & No & Yes & Yes & Yes & 12.7 \\
\hline 12 & 65 & $F$ & Idiopathic & 16 & Yes & No & Both & Yes & - & Yes & Yes & 11 \\
\hline 13 & 72 & $\mathrm{~F}$ & Idiopathic & 5 & Yes & Yes & Both & Yes & Yes & No & Yes & 9.6 \\
\hline 14 & 79 & $\mathrm{M}$ & Paraneoplastic & 4 & Yes & No & Lower only & Yes & - & Yes & Yes & 9 \\
\hline 15 & 76 & $M$ & Paraneoplastic & 5 & Yes & No & Lower only & Yes & - & Yes & Yes & 9 \\
\hline 16 & 71 & M & Paraneoplastic & 6 & Yes & No & Lower only & Yes & - & No & Yes & 5.9 \\
\hline 17 & 77 & M & Paraneoplastic & 1 & Yes & Yes & Both & Yes & - & Yes & Yes & 12.7 \\
\hline 18 & 68 & $\mathrm{~F}$ & Paraneoplastic & 2 & Yes & No & Both & Yes & Yes & Yes & No & 11 \\
\hline 19 & 60 & $\mathrm{~F}$ & Sjögren's & 6 & Yes & Yes & Both & No & No & Yes & Yes & 9.9 \\
\hline 20 & 65 & $\mathrm{~F}$ & Sjögren's & 5 & Yes & No & Upper only & Yes & - & Yes & Yes & 11 \\
\hline 21 & 51 & $\mathrm{~F}$ & Sjögren's & 12 & Yes & Yes & Both & Yes & - & Yes & Yes & 12.7 \\
\hline 22 & 71 & F & Sjögren's & 27 & Yes & No & Both & Yes & - & No & Yes & 7.9 \\
\hline 23 & 73 & $\mathrm{~F}$ & Sjögren's & 21 & Yes & No & Both & Yes & - & Yes & No & 11 \\
\hline 24 & 65 & F & Sjögren's & 7 & No & Yes & Upper only & No & No & Yes & Yes & 6.8 \\
\hline 25 & 67 & $\mathrm{M}$ & Sjögren's & 1 & Yes & Yes & Both & Yes & - & Yes & Yes & 12.7 \\
\hline 26 & 75 & $M$ & Sjögren's & 7 & No & No & Upper only & Yes & - & Yes & Yes & 7.9 \\
\hline
\end{tabular}

$\mathrm{F}=$ female; $\mathrm{M}=$ male; $\mathrm{SNAP}=$ sensory nerve action potential; $\mathrm{LLN}=$ lower limit of normal. 
Table 2: Demographic, etiological, diagnostic score and BR data for all patients

\begin{tabular}{|c|c|c|c|c|c|c|c|c|c|c|c|}
\hline \multirow[b]{2}{*}{ Patient } & \multirow[b]{2}{*}{ Age } & \multirow[b]{2}{*}{ Sex } & \multirow[b]{2}{*}{ Etiology } & \multirow[b]{2}{*}{$\begin{array}{l}\text { Diagnostic } \\
\text { criteria score }\end{array}$} & \multicolumn{3}{|c|}{ Right stimulation } & \multicolumn{3}{|c|}{ Left stimulation } & \multirow[b]{2}{*}{ Blink reflex } \\
\hline & & & & & R1 & iR2 & cR2 & R1 & iR2 & cR2 & \\
\hline 1 & 69 & M & Gluten/celiac & 12.7 & 11.4 & 32 & 35.6 & 11 & 35 & 36 & Normal \\
\hline 2 & 41 & $\mathrm{~F}$ & Gluten/celiac & 6.8 & 10.6 & 30 & 29.9 & 10.7 & 31.8 & 30 & Normal \\
\hline 3 & 61 & M & Gluten/celiac & 9.9 & 10.8 & 50 & 50.8 & 9.8 & NR & NR & $\begin{array}{l}\text { Delayed } \mathrm{iR} 2 / \mathrm{cR} 2 \text { on right, absent } \\
\mathrm{iR} 2 / \mathrm{cR} 2 \text { on left }\end{array}$ \\
\hline 4 & 20 & M & Friedreich's & 11 & 10.3 & 36 & 40.6 & 10.7 & 34.4 & 35 & Normal \\
\hline 5 & 24 & M & Friedreich's & 11 & 9.1 & 42 & 39.4 & 9.7 & 40.2 & 43 & Delayed iR2 on right \\
\hline 6 & 20 & F & Friedreich's & 11 & 9.4 & 39 & 42 & 9.7 & 38.2 & 43 & Normal \\
\hline 7 & 76 & F & Idiopathic & 10.7 & 13 & 30 & 33.5 & 12.6 & 26.1 & 26 & Normal \\
\hline 8 & 67 & $\mathrm{~F}$ & Idiopathic & 12.7 & 9.8 & 34 & 30.8 & 10.5 & 35.4 & 34 & Normal \\
\hline 9 & 73 & $\mathrm{~F}$ & Idiopathic & 11 & 9.1 & 33 & 30.8 & 9.5 & 36.4 & 33 & Normal \\
\hline 10 & 73 & F & Idiopathic & 4.8 & 10.8 & 42 & 41.2 & 10.4 & 40.4 & 43 & Delayed $\mathrm{iR} 2$ on right \\
\hline 11 & 54 & M & Idiopathic & 12.7 & 10.2 & 37 & 36.6 & 11.2 & 37.4 & 36 & Normal \\
\hline 12 & 65 & F & Idiopathic & 11 & 11.6 & 39 & 40.4 & 10.6 & 37.5 & 42 & Normal \\
\hline 13 & 72 & $\mathrm{~F}$ & Idiopathic & 9.6 & 14 & 36 & 37.5 & 14.1 & 31.8 & 31 & Delayed R1 bilaterally \\
\hline 14 & 79 & M & Paraneoplastic & 9 & 12 & 37 & 38 & 10.1 & 42.8 & 45 & $\begin{array}{l}\text { Relative delay of R1 on right, } \\
\text { delayed } \mathrm{iR} 2 / \mathrm{cR} 2 \text { on left }\end{array}$ \\
\hline 15 & 76 & M & Paraneoplastic & 9 & 11 & 42 & 41 & 10.9 & 40.4 & 39 & Delayed $\mathrm{iR} 2$ on right \\
\hline 16 & 71 & M & Paraneoplastic & 5.9 & 10.8 & 33 & 34 & 10.8 & 36.1 & 34 & Normal \\
\hline 17 & 77 & M & Paraneoplastic & 12.7 & 10.2 & 32 & 31.3 & 9.2 & 37.9 & 30 & Relative delay of iR2 on left \\
\hline 18 & 68 & $\mathrm{~F}$ & Paraneoplastic & 11 & NR & 31 & 33.2 & NR & 29.5 & 31 & Absent R1 bilaterally \\
\hline 19 & 60 & F & Sjögren's & 9.9 & 10.5 & 36 & 34.6 & 10.9 & 33.2 & 34 & Normal \\
\hline 20 & 65 & F & Sjögren's & 11 & 10.2 & 32 & 31.6 & 10.9 & 34.2 & 32 & Normal \\
\hline 21 & 51 & F & Sjögren's & 12.7 & 11.6 & 36 & 36 & 12 & 37.4 & 35 & Normal \\
\hline 22 & 71 & F & Sjögren's & 7.9 & 9 & 32 & 34.6 & 9.4 & 34.1 & 35 & Normal \\
\hline 23 & 73 & F & Sjögren's & 11 & 10.4 & 38 & 38.8 & 10.5 & 39.1 & 40 & Normal \\
\hline 24 & 65 & F & Sjögren's & 6.8 & 9.6 & 33 & 33.5 & 9.8 & 36.8 & 36 & Normal \\
\hline 25 & 67 & M & Sjögren's & 12.7 & 8.6 & 47 & 48.9 & 9.2 & 39.3 & 39 & Delayed iR2/cR2 on right \\
\hline 26 & 75 & $\mathrm{M}$ & Sjögren's & 7.9 & 11 & 33 & 32.4 & 11.7 & 33.2 & 32 & Normal \\
\hline
\end{tabular}

Figures in red indicate values outside of normal range. R1 and R2 latency values are in milliseconds. Maximum latency is $13 \mathrm{~ms}$ for R1, $41 \mathrm{~ms}$ for IR2, and $44 \mathrm{~ms}$ for cR2. The maximum side-to-side difference in latency is $1.8 \mathrm{~ms}$ for R1 and $5.7 \mathrm{~ms}$ and $9.4 \mathrm{~ms}$ for ipsilateral and contralateral R2, respectively. $\mathrm{BR}=$ blink reflex; $\mathrm{cR} 2=$ contralateral $\mathrm{R} 2 ; \mathrm{iR} 2=$ ipsilateral $\mathrm{R} 2 ; \mathrm{F}=$ female; male $=$ male.

Our finding of R2 abnormality with preservation of the R1 latency in patients with Friedreich's ataxia is similar to findings from a previous study examining BR and auditory evoked potentials in this group of patients. ${ }^{19}$ Intriguingly, an autopsy of a patient with Friedreich's ataxia demonstrated loss of secondary sensory neurons in the trigeminal nuclei, ${ }^{20}$ an observation that would manifest on the BR as prolongation/ absence of the R2 component. We are not aware of any neuropathological studies looking at the Gasserian ganglion in cases of confirmed SG.

An important observation in our study is the finding of abnormal BR responses in paraneoplastic cases. It has previously been reported that the BR is normal in SG seen in association with malignancy ${ }^{11}$; however, we found abnormalities in four of five patients. Although such patient numbers are small, this is in clear contrast to the previous report in which no BR abnormalities were reported in 17 cases of paraneoplastic SG. Although some of the patients with a paraneoplastic SG had only mild R2 abnormalities that one might argue are of equivocal significance, two patients had abnormalities of the R1, which is a robust marker of pathology. The disparity between our findings and those of previous studies could relate to the patchy nature of such disease.

In conclusion, we report BR abnormalities in $34.6 \%$ of our SG cohort. The most common abnormality was prolongation of the R2 component, although R1 abnormalities were seen in one-third of those with an abnormal BR. The most likely cause of the BR abnormality is pathology at the level of the Gasserian ganglion, although involvement of the central polysynaptic pathways could also potentially cause abnormalities of the R2 response. Finally, BR abnormalities can be seen in SG related to paraneoplasia. 


\section{DisClOSURES}

TA, ASEB, JJPA, MH, and DGR do not have anything to disclose.

\section{REFERENCES}

1. Sghirlanzoni A, Pareyson D, Lauria G. Sensory neuron diseases. Lancet Neurol. 2005;4:349-61.

2. Koeppen AH. Friedreich's ataxia: pathology, pathogenesis, and molecular genetics. J Neurol Sci. 2001;303:1-12.

3. Graus F, Delattre JY, Antoine JC, et al. Recommended diagnostic criteria for paraneoplastic neurological syndromes. J Neurol Neurosurg Psychiatry. 2004;75(8):1135-40.

4. Griffin JW, Cornblath DR, Alexander E, et al. Ataxic sensory neuropathy and dorsal root ganglionitis associated with Sjögren's syndrome. Ann Neurol. 1990;27:304-15.

5. Hadjivassiliou M, Rao DG, Wharton SB, Sanders SB, Grünewald RA, Davies-Jones AG. Sensory ganglionopathy due to gluten sensitivity. Neurology. 2010;75:1003-8.

6. Camdessanche JP, Jousserand G, Ferraud K, et al. The pattern and diagnostic criteria of sensory neuronopathy: a case-control study. Brain. 2009;132:1723-33.

7. Esteban A. A neurophysiological approach to brainstem reflexes. Blink reflex. Neurophysiol Clin. 1999;29:7-38.

8. Mori K, Iijima M, Koike H, et al. The wide spectrum of clinical manifestations on Sjögren's syndrome-associated neuropathy. Brain. 2005;128:2518-34.

9. Koike $\mathrm{H}$, Atsuta $\mathrm{N}$, Adachi $\mathrm{H}$, et al. Clinicopathological features of acute autonomic and sensory neuropathy. Brain. 2010;133:2881-96.
10. Koike H, Tnaka F, Sobue G. Paraneoplastic neuropathy: wide-ranging clinicopathological manifestations. Curr Opin Neurol. 2011;24:504-10.

11. Auger RG, Windebank AJ, Lucchinetti CF, Lucchinietti CF, Chalk $\mathrm{CH}$. Role of the blink reflex in the evaluation of sensory neuronopathy. Neurology. 1999;53:407-8.

12. Malinow K, Yannakakis GD, Glusman SM, et al. Subacute sensory neuronopathy secondary to dorsal root ganglionitis in primary Sjögren's syndrome. Ann Neurol. 1986;20:535-7.

13. Trujillo-Hernandez B, Huerta M, Perez-Vargas D, Xochitl Trujillo, Vasquez C. Blink reflex alterations in recently diagnosed diabetic patients. J Clin Neurosci. 2003;10:306-9.

14. Nazliel B, Yetkin I, Irteç C, Koçer B. Blink reflex abnormalities in diabetes mellitus. Metab Res Rev. 2001;17:396-400.

15. Preston DC, Shapiro BE. Electromyography and neuromuscular disorders, 2nd edition. Philadelphia, PA: Elsevier; 2005.

16. Valls-Sole J, Graus F, Font J, Pou A, Tolosa ES. Normal proprioceptive trigeminal afferents in patients with Sjögren's syndrome and sensory neuronopathy. Ann Neurol. 1990;28:786-90.

17. Shahani B. The human blink reflex. J Neurol Neurosurg Psychiatry. 1970;33:792-800.

18. Leis AA, Kofler M, Ross MA. The silent period in pure sensory neuronopathy. Muscle Nerve. 1992;15:1345-8.

19. De Pablos C, Berciano J, Calleja J. Brain-stem auditory evoked potentials and blink reflex in Friedreich's ataxia. J Neurol. 1991;238:212-6.

20. Jitpimolmard S, Small J, King RHM, et al. The sensory neuropathy of Friedreich's ataxia: an autopsy study of a case with prolonged survival. Acta Neuropathol. 1993;86:29-35. 